Revista de Ciencias Sociales - Número 69 (2016) - Páginas 91-119

La cláusula constitucional de igualdad en clave de género: hacia un nuevo...

\title{
LA CLÁUSULA CONSTITUCIONAL DE IGUALDAD EN CLAVE DE GÉNERO: HACIA UN NUEVO MODELO CIUDADANÍA
}

\author{
THE CONSTITUTIONAL EQUALITY CLAUSE WITH \\ A GENDER PERSPECTIVE: TOWARDS \\ A NEW CITIZENSHIP MODEL
}

\author{
CECILIA VALENZUELA OYANEDER* \\ Programa de Doctorado Universidad Diego Portales \\ valenzuelaoyaneder@gmail.com
}

\section{Resumen}

Tanto la igualdad formal como la sustantiva no han sido capaces de configurar un modelo de ciudadanía para las mujeres que les permita concurrir con pleno despliegue de sus capacidades al demos. Ello, debido al sistema opresivo de carácter estructural conforme al cual se ha organizado el orden social. Es por lo anterior que dicho orden debe ser reestructurado, y para ello, los roles de género deben ser puestos en tensión. Desde una perspectiva jurídica, esta labor implica reinterpretar el principio de igualdad, desde una perspectiva de género fundada en las teorías feministas, a fin de abordar, políticamente, los asuntos de crianza, cuidado y reproducción — hasta ahora

* Doctoranda en Derecho de la Universidad Diego Portales, Magíster en Derecho Constitucional, Abogada y Licenciada en Ciencias Jurídicas y Sociales de la Universidad de Valparaíso, Valparaíso, Chile. Artículo recibido el 30 de noviembre de 2016 y aceptado el 12 de diciembre de 2016.

Revista de Ciencias Sociales - Número 69 (2016) - Universidad de Valparáíso - ISSN 0716-7725-Valparáiso, Chile 
reducidos al ámbito de lo privado-, aspirando con ello a un nuevo concepto de ciudadanía de los géneros, que proyectará una redistribución de derechos y deberes relacionados con el cuidado, la crianza y la reproducción.

\section{Palabras clave}

Mujeres, igualdad, roles de género, Crianza, cuidado, reproducción.

\section{Abstract}

Formal and substantive equality have not been able to configure a model of citizenship for women that entitle them with the full deployment of their capabilities into demos. This is due to the structural oppressive system under which the social order has been organized. For that reason, this order must be restructured, and the gender roles must be put in tension. From a juridical point of view, this task supposes the reinterpretation of the principle of equality from a gender perspective grounded in the feminist theories, in order to address matters about breeding, caring and reproduction politically,until now reduced to the private sphere-, aiming a new concept of gender citizenship, which will project a redistribution of rights and duties related to the breeding, caring and reproduction.

\section{Keywords}

Women, equality, gender roles, breeding, caring, reproduction.

\section{Introducción}

Tal como se ha interpretado el principio de igualdad a nivel global, éste no ha sido capaz de configurar un modelo de ciudadanía para las mujeres que permita desarrollar plenamente sus capacidades. Para ilustrar ello, en nuestra realidad, considérense tres ejes centrales en la vida de las chilenas, en tanto ciudadanas, a saber: su participación en cargos de elección popular, el libre ejercicio del control de sus cuerpos y la manera en que las labores de cuidado, crianza y reproducción les están asignadas. Observados estos puntos, no se tardará en afirmar que su calidad de ciudadanas, no es más que un pálido reflejo de la de los varones. En efecto, las mujeres representan, aproximadamente, el 13\% de los cargos del Parlamento, lo que pone en tensión a la democracia

Facultad de Derecho y Ciencias Sociales - Universidad de Valparaíso - Chile 
representativa ${ }^{1}$; les está prohibido ejercer el control autónomo de sus cuerpos para efectos de interrumpir el embarazo ${ }^{2}$ y; pese a las últimas modificaciones legales, es en la madre en quien, tradicionalmente, han descansado las labores de cuidado, crianza y reproducción.

En cuanto el primer problema, éste se ha abordado por medio de un sistema de cuotas de género que busca asegurar que al menos el $40 \%$ de las candidaturas para cargos de elección popular sean femeninas. En relación al segundo, actualmente se encuentra en discusión un proyecto de ley para despenalizar el aborto en tres causales (embarazo por violación, inviabilidad fetal de carácter legal y peligro de muerte de la madre). Sin embargo, en lo que respecta al último punto, aún se está en deuda con una revalorización y (re)distribución de las labores de cuidado, crianza y reproducción, que ponga en tensión los roles tradicionales de género en clave constitucional.

La ciudadanía de "segunda clase" de las mujeres, de la que dan cuenta estos tres ejes — su lejanía con los cargos de poder, la falta de autonomía del control de sus cuerpos y su dedicación casi exclusiva y sin reconocimiento hacia las labores de cuidado, crianza y reproducción - responde a un contexto de opresión estructural de nivel global que subyace "a la propia estructura de nuestras sociedades, a la forma en que [se organiza] el Estado y, por cierto, al modo en que [se comprende] el Derecho" ${ }^{3}$. El calificativo "opresivo", siguiendo a Young,

1. En relación a la admisibilidad y pertinencia de las cuotas electorales, véase ZÚNIIGA, Yanira: "Democracia paritaria: de la teoría a la práctica". En: Revista de Derecho (Valdivia), XVIII, No 2, 2005. Págs. 131-154; AGUILERA, Daniela, VÁSQUEZ, Andrea y ZÚÑIGA, Alejandra: "Lejos del poder. Hacia la implementación de una ley de cuotas en Chile". En: Revista de Derecho (Valdivia), XX, No 2, 2007. Págs. 9-30 y; VALENZUELA, Cecilia y ZÚÑIGA, Alejandra: "Leyes de cuotas electorales, constitución y democracia”. En: Revista de Derecho (Valdivia), XXVII, $\mathrm{N}^{\circ}$ 1, 2014. Págs. 191-211.

2. Sobre la necesidad de consagrar constitucionalmente los derechos sexuales y reproductivos de las mujeres, véase VALENZUELA, Cecilia y VILLAVI-

CENCIO, Luis: "La constitucionalización de los derechos sexuales y reproductivos. Hacia una igual ciudadanía para las mujeres”. En: Revista Ius et Praxis, Año 21, N 1 , 2015. Págs. 271-314.

3. VILLAVICENCIO, Luis y ZÚÑIGA, Alejandra: "La violencia de género como opresión estructural”. En Revista de Derecho, vol. 42, N (2015). Pág. 720.

Revista de Ciencias Sociales - Número 69 (2016) - Universidad de Valparáíso - ISSN 0716-7725-Valparaíso, Chile 
comprende toda acción u omisión de quienes ejercen el poder, capaz de poner desventaja o en situación de injusticia a ciertos grupos de la sociedad, incluso cuando no existe voluntad de provocar aquello ${ }^{4}$. En el caso de las mujeres, continua la autora, la opresión consiste, en parte, en una transferencia sistemática y no recíproca de poderes a los hombres, que implica más que una desigualdad de estatus, poder y riqueza resultante de la práctica cultural por la cual los hombres han excluido a las mujeres de las actividades privilegiadas, ya que esa desigualdad es posible precisamente porque las mujeres trabajan para ellos. De este modo, la explotación de género se inicia con la transferencia a los hombres de los frutos del trabajo material y de las energías sexuales y de crianza de las mujeres lo que no se modificará a menos que lo haga la estructura social y cultural ${ }^{5}$.

En lo que respecta al Derecho, éste cobra una importante función en la labor de desbaratar las estructuras socio-culturales opresivas sobre las que se plantea la sociedad, sin dejar de olvidar que - y en consonancia con lo anteriormente señalado - hasta ahora éste ha formado parte de la "red estructural sistémica de instituciones sociales" a la que pertenecen, y oprimen a las mujeres ${ }^{6}$. Por ello, es fundamental comprender que la interpretación y aplicación del Derecho deben realizarse desde una perspectiva de género (gender mainstreaming) fundada en las teorías feministas.

4. En términos de Young, "la opresión designa las desventajas e injusticias que sufre alguna gente no porque un poder tiránico la coaccione, sino por las prácticas cotidianas y estructurales de una bien intencionada sociedad liberal (...). Pero la opresión se refiere también a los impedimentos sistemáticos que sufren algunos grupos y que no necesariamente son el resultado de las intenciones de un tirano. La opresión así entendida es estructural y no tanto el resultado de las elecciones o políticas de unas pocas personas. Sus causas están insertas en normas, hábitos y símbolos que no se cuestionan, en los presupuestos que subyacen a las reglas institucionales y en las consecuencias colectivas de seguir esas reglas YOUNG, Iris: La justicia y la política de la diferencia. Ediciones Cátedra, Madrid, 2000. Pág. 74.

5. Ibíd., págs. 89-93.

6. HAY, Carol: Kantianism, Liberalism and Feminism. Resisting Oppression, Palgrave Macmillan, New York, 2013. Pág. 33.

Facultad de Derecho y Ciencias Sociales - Universidad de Valparaíso - Chile 
Bajo este orden de ideas, propongo plantear la interpretación de la cláusula constitucional de igualdad, desde una perspectiva de género fundada en las teorías feministas, como una labor clave para la reconceptualización de la ciudadanía de género, por cuanto dicho principio será la herramienta normativa que, a través de su hermenéutica, permitirá cuestionar y poner en tensión los roles que se les han asignado a las mujeres y a los hombres en razón de su género. Específicamente, este trabajo se centrará en los roles de cuidado, crianza y reproducción. Para ello, el trabajo se dividirá en tres partes. En la primera, se examinará la falsa promesa emancipatoria de la Modernidad en lo que concierne a las mujeres, en tanto ciudadanas. En la segunda, se revisarán los modelos de igualdad de los sexos desarrollados en Estados Unidos y Europa. En la tercera parte, se planteará una vía alternativa de aproximación a la relación de subordinación entre los sexos en base a la revalorización de las labores de cuidado y reproducción y al cuestionamiento de los roles de género. Finalmente, se plantearán algunas conclusiones.

\section{Una reivindicación de derechos en clave masculina: la división del orden social y el repliegue de las mujeres al hogar}

El espíritu emancipatorio y libertario de la modernidad no alcanzó para las mujeres. Lejos de ser una época de reivindicación de derechos para ellas, su construcción en clave masculina acabó por romper la promesa de la universalidad del derecho pues, la vindicación fue respecto de la individualidad, autonomía y los derechos de la mitad de la especie humana, los hombres. De ello han derivado "múltiples escollos para incluir la perspectiva de género en el mundo jurídico, debido a su habilidad para reproducir el modelo de la dominación masculina y a su intención manifiesta (o implícita) de dejar a las mujeres apartadas del espacio público" 7 .

Siguiendo a C. Pateman, el relego de las mujeres a lo doméstico, tuvo lugar por la división que dio por establecida el contrato social entre la esfera de lo público y lo privado; escisión que proyecta la diferencia

7. VALENZUELA, Cecilia y VILLAVICENCIO, Luis, ob. cit., pág. 272.

Revista de Ciencias Sociales - Número 69 (2016) - Universidad de Valparaíso - ISSN 0716-7725-Valparáís, Chile 
sexual, la que a su vez constituye una diferencia política. Es decir, la diferencia sexual es la diferencia entre libertad y sujeción. Este destierro fundado en la división de esferas, de acuerdo con la autora, forma parte de la historia reprimida de la teoría del contrato que, en cuanto tal, es una parte integral de la elección racional del familiar acuerdo original, a la que denomina: el contrato sexual. Este singular acuerdo da cuenta de la manera en que se establece una forma específicamente moderna de patriarcado, explicando la creación de aquella parte del orden social, la esfera privada, que quedó fuera de análisis y reconocimiento en el relato del contrato social, por no considerarse políticamente relevante ${ }^{8}$.

Así, el conocido pacto original es tanto un pacto social como sexual. Su carácter sexual está dado por el hecho de que es "patriarcal - es decir, el contrato establece el derecho político de los varones sobre la mujeres - [y porque] establece un orden de acceso de los varones al cuerpo de las mujeres"

Tal como se señaló recién, la diferencia sexual definirá la diferencia entre libertad y sujeción. Así, bajo el paradigma contractual de la modernidad, los varones detentarán los atributos de los "individuos" libres e iguales, mientras que las mujeres nacerán en sujeción, por cuanto "las capacidades y atributos naturales están sexualmente diferenciados" ${ }^{10}$. En otros términos, en esta dinámica de diferenciación sexual que se proyecta a nivel político, los varones que celebran el pacto social, serán considerados como "los iguales", "mientras que las mujeres, al no ostentar el atributo de la igualdad, sino que, como señala Amorós, son heterodesignadas como las idénticas, [quedarán] excluidas como sujetos del contrato, aunque no así como objetos de transacción de éste" ${ }^{11}$. Y es que, la diferencia sexual justifica

8. PATEMAN, Carol: El contrato sexual. Barcelona: Anthropos, México: Universidad Autónoma Metropolitana-Iztapalapa, Trad. María Luisa Femenías, 1995. Págs. 8-15.

9. Ibíd., pág. 11.

10. Ibíd., págs. 60 y 61 .

11. SÁNCHEZ, Cristina: "Genealogía de la vindicación”. En: Beltrán, Elena y Maquieira, Virginia: Feminismo. Debates teóricos contemporáneos. Alianza, Madrid, 2008. Pág. 22.

Facultad de Derecho y Ciencias Sociales - Universidad de Valparaíso - Chile 
que las mujeres se consideren imposibilitadas para ser individuos civiles, pues "son naturalmente deficitarias de la capacidad específicamente política, la capacidad para crear y conservar el derecho político" ${ }^{12}$. De este modo, esta diferencia política derivada de la diferencia sexual, explicará la ausencia de las mujeres en la formación "del contrato originario a través del cual los hombres transforman su libertad natural en la seguridad de la libertad civil"13.

Ante al fraude de las promesas modernas, los movimientos feministas han librado diferentes batallas. Entre ellas destaca la de las sufragistas, quienes lucharon no sólo por la obtención del voto de la mujer, sino también por su acceso a la educación y al trabajo ${ }^{14}$. Sin embargo, y pese a lo significativo de estos logros, en la práctica, el orden social siguió y sigue siendo masculino. En efecto, con la llegada del constitucionalismo a mediados del siglo XX, y no obstante su discurso basado en los derechos humanos, las mujeres continuaron en un segundo orden. De hecho, su situación no sólo se perpetuó sino que fue ratificada por los nuevos textos constitucionales de postguerra, los que reavivaron el rol de las mujeres en las labores de crianza y reproducción, enarbolando la institución de la familia como núcleo fundamental de la sociedad, como "un repositorio del cuidado y la dependencia, que merece el reconocimiento y protección del estado"15. Sobre este punto, Y. Zúñiga precisa que durante este período las mujeres vuelven a sus hogares ya que la fuerza de trabajo regresa a casa, aumentando con ello la natalidad, lo que provocará "un caldo de cultivo suficiente para el surgimiento de lo que Betty Friedan denominó la Mística de la Feminidad, es decir, una confluencia de esfuerzos sociales, más o menos consientes, tendentes a "re-encantar" a las mujeres con el

12. PATEMAN, Carol: El contrato..., ob. cit., págs. 133-135.

13. Ibíd., pág. 15.

14. ZÚÑIGA, Yanira: "La "generización” de la ciudadanía. Apuntes sobre el rol de la diferencia sexual en el pensamiento feminista". En: Revista de Derecho (Valdivia), XXII, N², 2009. Pág. 43.

15. RUBIO-MARÍN, Ruth: "The (dis)establishment of gender: Care and gender roles in the family as a constitutional matter". En: International Journal of Constitutional Law, vol. 13, $\mathrm{N}^{\circ}$ 4, 2015. Pág. 794.

Revista de Ciencias Sociales - Número 69 (2016) - Universidad de Valparáíso - ISSN 0716-7725-Valparáiso, Chile 
espacio doméstico y cuyo eje será la exaltación de la maternidad. (...) El mensaje era claro: la recién conquistada ciudadanía política y el acceso a la educación y al trabajo no doméstico no debían interferir con las necesidades de administración del hogar y cuidado de la familia" ${ }^{16}$. En otras palabras, tal como lo plantea Rubio-Marín, las interpretaciones de las cláusulas de igualdad, acabaron por ser compatibles con un orden social en el que, al interior de las familias, hombres y mujeres tenían asignados roles diferentes ${ }^{17}$.

En Alemania, por ejemplo, durante la década del 50 y del 60, no obstante considerarse inconstitucional el elemento de la subordinación de la familia tradicional, no se cuestionan los ejes de separación/ diferenciación. Así, al interpretar la igualdad de género y la cláusula de antidiscriminación sexual constitucional, la Corte Constitucional Federal abrió el paso a los tratamientos diferentes de género, en la medida que se fundaran en diferencias sexuales biológicas o funcionales y ello implicara una ventaja de las mujeres. A esta doctrina se le conoció como la doctrina del tratamiento "separate but equal", cuya constitucionalidad dependía de que se "le asignara igual valor a los roles de las mujeres y de los hombres en la familia"18.

Luego, no será sino hasta la década del 60 y 70, que se dan los primeros pasos tendientes a alterar el orden de género. En efecto, la conocida "segunda ola del feminismo" cuestionó el destierro de las mujeres a la esfera privada, y con ello la organización dicotómica público/privado del orden social. De acuerdo a Y.Zúñiga, hasta entonces, la idea dominante a todo nivel, incluso en los movimientos feministas, era que "las mujeres estaban estrechamente ligadas a la esfera doméstica y que eran sus principales responsables. Así surge el famoso eslogan de "lo personal es político" ${ }^{\text {, }}$ que reivindica el control de la sexua-

16. ZÚNIIGA, Yanira: "La "generización” de la ciudadanía...”, ob. cit., pág. 43.

17. RUBIO-MARÍN, Ruth, ob. cit, pág. 794.

18. Ibíd., p.795.

19. El eslogan "lo personal es político", afirma Villavicencio y Zúñiga, da cuenta del "carácter ideológico de los supuestos en los que se sustenta la distinción liberal entre lo público y lo privado, tributarios del patriarcado (...). [Siguiendo a Pateman, los autores precisan que el énfasis feminista por destacar el modo en que] "las circunstancias personales están estructuradas por factores públicos, por leyes sobre

Facultad de Derecho y Ciencias Sociales - Universidad de Valparaíso - Chile 
lidad y que establece el primer puente entre lo privado y lo público"20.

Conforme a esta nueva tendencia, las cortes a nivel global comenzaron a plantear la necesidad de "vencer el estatus marital diferente de las mujeres y de expandir su rol más allá de la familia, asegurando cada vez más la igualdad de las mujeres en el mercado"21. De este modo, en el marco de este nuevo desafío fundado en las cláusulas constitucionales de igualdad, se advirtieron dos doctrinas, la de la igualdad formal de los sexos, denominada asimilacionista, propia de Estados Unidos, y la de la igualdad sustantiva, denominada acomodacionista, asentada en Europa. Ambas serán revisadas a continuación.

\section{Sobre las doctrinas de la igualdad de los sexos: nuevas desilusiones}

\subsection{Doctrina norteamericana asimilacionista}

Siguiendo a Levyt y Verchick, sobre la base del principio de la igualdad formal — mismo que inspiró el movimiento sufragista—, la doctrina del igual tratamiento se fundó en ideales liberales filosóficos y de la teoría política que apoyaron la igualdad de la ciudadanía y la igualdad de oportunidades en la arena política, junto con el individualismo y la racionalidad. Esta doctrina postula que la ley debe tratar de igual manera a hombres y mujeres en la medida que se encuentren en una situación similar, y sus decisiones no deben fundarse en generalizaciones acerca de las mujeres como grupo. Los objetivos de la igualdad de tratamiento son obtener oportunidades sociales y políticas equivalentes y acabar con la legislación que intenta proteger a la mujer y aislarla de la esfera pública. Entre 1970 y 1980, la táctica de la igualdad

violación (...) y por el estatus de "esposa”, por políticas relativas al cuidado de los niños, por la asignación de subsidios del Estado de bienestar y por la división sexual del trabajo en el hogar y fuera de él, [acaba por demostrar que] los problemas "personales" solo se pueden resolver a través de medios y de acciones políticas"”. VILLAVICENCIO, Luis y ZÚÑIGA, Alejandra, ob. cit., pág. 720.

20. ZÚÑIGA, Yanira: “La “generización” de la ciudadanía...”, ob. cit., pág. 50.

21. RUBIO-MARÍN, Ruth, ob.cit., pág. 796.

Revista de Ciencias Sociales - Número 69 (2016) - Universidad de Valparáíso - ISSN 0716-7725-Valparaíso, Chile 
formal fue exitosa en eliminar las barreras específicas para el tratamiento igualitario, sin embargo, ésta se enfocó en el ámbito de las actividades públicas descuidando las conductas personales. Lo característico de esta doctrina, y que le significó la mayoría de sus críticas, fue que aceptó la experiencia del hombre como la referencia de la norma; por tanto, las mujeres alcanzan la igualdad sólo en la medida que ellas se sitúen junto a los hombres ${ }^{22}$. Esto último resultó así, pese a que no estaba en los propósitos de los creadores de la teoría anti-estereotipo de la igualdad sexual negar el valor central de la reproducción humana y del cuidado, sino desafiar los roles de género y las expectativas en torno a ellos ${ }^{23}$.

Estados Unidos desarrolló esta doctrina y, conforme a su lógica, su jurisprudencia consideró inconstitucional todas aquellas leyes basadas en estereotipos sexuales. Así, el país del norte impulsó una doctrina que propendía hacia la igualdad de los sexos, la que se calificó como "asimilacionista" por cuanto "las normas debían ignorar las diferencias funcionales entre los sexos de manera de liberar al individuo de las expectativas que podrían imponérsele" ${ }^{24}$. Norteamérica entendió que la única vía posible para derribar "la construcción patriarcal de la sexualidad [era] eliminar la diferencia sexual y hacer de la masculinidad y la femineidad algo políticamente irrelevante. [Por ello, fueron determinantes las campañas de las feministas liberales o de la igualdad] para lograr reformas legales que se incluyen en lo que ahora suele denominarse términos de "género neutro"” 25.

Esta doctrina no tardó en encontrar resistencias, por cuanto, de acuerdo a Pateman, si bien sus reformas salvaguardaron los derechos civiles de las mujeres, el patrón normativo, aunque aparentaba ser un “individuo" sexualmente neutro ${ }^{26}$, éste escondía el modelo del varón.

22. LEVYT, Nancy y VERCHICK, Robert: Feminist Legal Theory. A Primer. University Press, New York 2006. Págs. 16-18.

23. RUBIO-MARÍN, Ruth, ob.cit, pág. 799.

24. Ibíd., pág. 797.

25. PATEMAN, Carol: El contrato..., ob. cit., pág. 258.

26. Ibíd., pág. 213.

Facultad de Derecho y Ciencias Sociales - Universidad de Valparaíso - Chile 
Una de las fuerzas de resistencias fue el "feminismo cultural" o "feminismo de la diferencia", el cual planteó que las leyes neutrales, desde una perspectiva de género, pueden reducir a las mujeres por cuanto no reconocen las diferentes experiencias y perspectivas de las mujeres. Por ello, los hombres y las mujeres, no deberían ser tratados igual en aquellos aspectos en que son relevantemente diferentes, de modo que a las mujeres no se les debería exigir que se asimilaran a los hombres ${ }^{27}$.

Sobre este punto, vale la pena una pequeña digresión. Esta pretendida — aunque falsa — neutralidad del modelo de individuo con respecto a quién igualarse, es advertida y cuestionada, también, a nivel de la filosofía moral por Seyla Benhabib. Tal como lo señala E. Beltrán, la autora, desde la teoría crítica feminista, intenta matizar la idea de sujeto abstracto y autónomo planteada por la tradición universalista, reprochando el que "los autores del contractualismo clásico [apoyaran] sus pretensiones universalistas en una sustitución implícita del sujeto abstracto por un sujeto específico, con la consecuencia de excluir a las mujeres del punto de vista moral al privatizar su experiencia” ${ }^{28}$. En este sentido Benhabib conceptualiza a las las teorías morales universalistas occidentales como sustitucionalistas "en el sentido de que el universalismo que defienden es definido subrepticiamente al identificar las experiencias de un grupo específico de sujetos como el caso paradigmático de los humanos como tales. Estos sujetos invariablemente son adultos blancos y varones, propietarios o al menos profesionales. [Este universalimo sustitucionalista se distancia del que denomina] universalismo interactivo [el cual] (...) reconoce la pluralidad de modos de ser humano, y diferencia entre los humanos, sin inhabilitar la validez moral y política de todas estas pluralidades y diferencias" ${ }^{29}$. Con su

27. LEVYT, Nancy y VERCHICK, Robert, ob. cit., pág. 19.

28. BELTRÁN, Elena: "Justicia, democracia y ciudadanía: las vías hacia la igualdad”. En: Beltrán, Elena y Maquieira, Virginia: Feminismo. Debates teóricos contemporáneos. Alianza, Madrid, 2008. Pág. 196.

29. BENHABIB, Seyla: "El otro generalizado y el otro concreto: la controversia Kohlber-Gilligan y la teoría feminista”. En: Benhabib, Seyla y Cornella,

Revista de Ciencias Sociales - Número 69 (2016) - Universidad de Valparáíso - ISSN 0716-7725-Valparaíso, Chile 
reformulación del universalismo, Benhabib llama a incorporar, a través de este universalismo interactivo, en el discurso del otro generalizado ${ }^{30}$ el punto de vista del otro concreto ${ }^{31}$, pues, a su juicio si no "se supone el punto de vista del otro concreto no se puede llevar a cabo ninguna prueba coherente de universabilidad, pues carecemos de la información epistémica necesaria para juzgar si mi situación moral es "semejante" a la tuya o si no lo es"32.

El paréntesis anterior permite conectar la utilización de un modelo de individuo basado en los principios de la racionalidad y de universalidad - aunque falsamente neutro-, con la doctrina asimilacionista, pues ésta omite, también, el cuestionamiento del patrón con el que se aspira equiparar - coincidente con dicho modelo de individuo-. Además, la anterior referencia permite dar cuenta del modo en que, desde las propias categorías de la filosofía moral clásica, se pretende organizar el orden social: basado en el prototipo del varón, blanco y heterosexual, como estándar de ser humano.

Pese al valioso esfuerzo de la doctrina anti-estereotipo, de evitar consagrar la asignación de roles que subyace al orden social y la generización de lo público y lo privado, según Rubio-Marín, ésta no acabó por hacer lo suficiente para subvertirlos. Aunque claro, en un contexto como el norteamericano, dicha labor se vuelve cuesta arriba

Drucilla: Teoría Feminista y Teoría Crítica. Ensayos sobre la política de género en las sociedades de capitalismo tardío. Alfons el Magnànim, Institució Valenciana d'Estudis i Investigació, España, 1990. Pág. 127.

30. "El punto de vista del otro generalizado nos demanda considerar a todos y cada uno de los individuos como seres racionales, con los mismos derechos y deberes que desearíamos concedernos a nosotros mismos. Al asumir este punto de vista hacemos abstracción de la individualidad y la identidad concreta del otro (...)”. Ibíd., pág. 136.

31. "El punto de vista del otro concreto, por el contrario, nos demanda considerar a todos y cada uno de los seres racionales como un individuo con una historia, una identidad y una constitución afectivo-emocional concretas. Al asumir este punto de vista hacemos abstracción de lo que constituye lo común (...)”. Ibíd. pág. 146.

32. Ibíd. pág. 143.

Facultad de Derecho y Ciencias Sociales - Universidad de Valparaíso - Chile 
ante doctrinas constitucionales como las de la privacidad familiar, "que estrictamente [anclan] el cuidado y la reproducción en el terreno de la privacidad, [y que son] impenetrables a las consideraciones de igualdad de género" ${ }^{33}$. Por ello, es difícil advertir de qué modo la doctrina contraria a la consolidación de estereotipos de género podía, efectivamente, llevar a cabo dicha pretensión, si a la sazón no se intentaba traspasar el velo del hogar y reordenar la distribución de las labores de cuidado, crianza y reproducción. Sin querer restar valor a estas funciones, con su actitud tan respetuosa de la privacidad del hogar, permitió que el modelo al interior del orden familiar perpetuara la estereotipación de los géneros, con la consiguiente subvaloración de las mencionadas labores.

\subsection{Doctrina europea acomodacionista}

En lo que respecta a la doctrina europea de la igualdad de los sexos, pese a que converge temporalmente con la norteamericana, y que en sus inicios (década del 70) sostuvo con firmeza la igualdad formal entre hombres y mujeres, procediendo múltiples reformas en el área del derecho de familia y matrimonial que eliminaron desigualdades explícitamente consagradas en las leyes, ésta "permaneció leal a la antigua tradición de reconocer el rol distintivo y las necesidades de la maternidad, reflejando el sello de un estado de bienestar proteccionista, pretendiendo intervenir activamente para asistir a las madres, más que tomar directa responsabilidad en la reproducción humana y el cuidado" ${ }^{34}$. En efecto, la conocida doctrina "acomodacionista" siguió la lógica de la igualdad sustantiva/anti-subordinación y sobre esta base confirmó la diferenciación de tratamientos mientras esta apuntara a "asegurar la igualdad de oportunidades de las mujeres, especialmente considerando sus roles como madres" 35 .

La doctrina acomodacionista se distingue de la asimilacionista, porque no intenta reducir la maternidad y el embarazo a parámetros

\footnotetext{
33. RUBIO-MARÍN, Ruth, ob. cit., pág. 800.

34. Ibíd., pág. 801.

35. Ibíd., pág. 802.
}

Revista de Ciencias Sociales - Número 69 (2016) - Universidad de Valparáíso - ISSN 0716-7725-Valparaíso, Chile 
neutros desde una perspectiva de género. Por el contrario, aquella intenta hacer compatibles las labores remuneradas con aquellas de cuidado que no lo son, especialmente respecto de las mujeres, haciendo un inevitable énfasis en su rol reproductivo y de cuidadora al interior de la familia ${ }^{36}$.

En esta línea, el Tribunal Constitucional español, afirma Balaguer, basado en la que consideraba la única diferencia entre el hombre y la mujer: la maternidad, a fines de la década de los 80 y principio de los 90, estima que ésta "repercute negativamente en su acceso y mantenimiento en el mercado de trabajo. Por esta razón, los poderes públicos han de contribuir a la supresión de esa dificultad, reforzando la posición jurídica de la mujer en aquellos supuestos en que se pretende romper el contrato de trabajo por causa del embarazo" ${ }^{37}$. Luego, esta contribución se manifiesta a través de políticas públicas que, en principio, privilegian a las mujeres. Digo "en principio" porque éstas acarrearán indeseados efectos, los cuales acusarán una importante deficiencia del modelo. $Y$ es que, al establecer condiciones diferentes "en favor" de las mujeres, a objeto de que puedan compatibilizar su vida doméstica y laboral —atendiendo las realidades generizadas vigentes_-, se debilita su contratación o facilitan la doble jornada de las mujeres (por las labores que realizan en el mercado laboral asalariado y en el hogar, gratuitamente), dando lugar a la llamada «mommy track»; figura que advierte formas diferentes de techos de cristal, caracterizados por la segregación en el mercado, con más mujeres que hombres en el sector informal y en el trabajo parcial, con pagos inferiores ${ }^{38}$.

Según puede advertirse, las doctrinas desarrolladas en Norteamérica y Europa no han abordado el asunto vital para poder reordenar la estructura social que se presenta en notorio desequilibrio (desfavorable) hacia las mujeres. En efecto, bajo el intento asimilacionista, tal como se señaló, las mujeres deben aspirar a alcanzar el

\footnotetext{
36. Ibíd., pág. 800.

37. BALAGUER, María, ob. cit., pág. 245.

38. RUBIO-MARÍN, Ruth ob. cit., pág. 802.
}

Facultad de Derecho y Ciencias Sociales - Universidad de Valparaíso - Chile 
lugar que hasta ahora los hombres han ocupado en la esfera pública, hacia allá se han destinado los esfuerzos y así se ha entendido logrado el mandato constitucional de igualdad. Por su parte, el modelo europeo, en el acto de valoración de las labores de cuidado y reproducción atribuidas a las mujeres, se les ha "protegido" para que puedan acceder al espacio público, al mercado y la política, principalmente, mediante medidas proteccionistas que, a largo plazo, han tenido un efecto inverso al buscado.

Estas tensiones y desilusiones que acompañan ambos modelos, cristalizan el denominado "dilema de Wollstonecraft" 39 , ya que, por un lado, de acuerdo al modelo norteamericano, las mujeres deben, a fin de cuentas, masculinazarse para alcanzar el estándar de la igualdad formal, y, por otro, conforme al modelo europeo, a las mujeres se les deben reconocer sus espacios diferentes que son, al final, los que las privan de ser protagonistas en lo público.

Cabe preguntarse entonces, hacia dónde deben dirigirse los esfuerzos para reacomodar el orden social. ¿Es correcto apuntar hacia una igualdad derechos entre los géneros sin cuestionar los roles de cada

39. "Mary Wollstonecraft argumentaba simultáneamente por la igualdad y el reconocimiento de la diferencia. Reclamaba iguales derechos civiles y políticos para las mujeres y la independencia económica de sus maridos, — declarando, "dejen a que la mujer que comparta los derechos y ella emulará las virtudes del hombre”y, al mismo tiempo, que la ciudadanía de las mujeres sea expresada de manera diferente a la de los hombres". Las mujeres tenían una "destinación peculiar" como madres, y su igual ciudadanía se expresaría a través de su maternidad (...) El dilema surge porque, dentro de la existente concepción patriarcal de la ciudadanía, la elección tiene que hacerse siempre entre la igualdad y la diferencia, o entre la igualdad y la condición de las mujeres [womanhood]. Por un lado, demandar la "igualdad" es luchar por la igualdad con los hombres (exigir que los "derechos del hombre y el ciudadano" se extiendan a las mujeres), lo que significa que las mujeres deben llegar a ser (como) los hombres. Por otro lado, insistir, como lo hacen algunas feministas contemporáneas, en que las actividades, capacidades y atributos de las mujeres deben ser revalorizados y tratados como una contribución a la ciudadanía es demandar lo imposible; tal "diferencia" es precisamente lo que excluye la ciudadanía patriarcal". PATEMAN, Carol: "Equality, difference, subordination: the politics of motherhood and Women's citizenship”. En: Bock, Gisela y James, Susan: Beyond equality and difference: citizenship, feminist politics and female subjectivity. Routledge, Londres y Nueva York, 2005. Pág. 17.

Revista de Ciencias Sociales - Número 69 (2016) - Universidad de Valparáíso - ISSN 0716-7725-Valparáiso, Chile 
uno de ellos, o, lo conveniente es subvertir los roles de género y a partir de ello redefinir el concepto de ciudadanía de género, consignando nuevos derechos y deberes para cada uno de ellos? A juicio de quien escribe, es esta última opción la manera correcta de hacer frente a la histórica situación de opresión de las mujeres, lo que por cierto, bajo el concepto de esta nueva definición de ciudadanía, también supondrá resultados positivos para los varones, tal como se observará a continuación.

\section{Repensar los roles de los géneros para un nuevo modelo de ciudadanía}

Pese a los esfuerzos por establecer condiciones más igualitarias para las mujeres, en tanto ciudadanas, el desequilibrio en relación con los varones permanece. Ello se debe, principalmente, a que las fuerzas se han concentrado en la incorporación de las mujeres en la esfera pública, ya sea bajo las condiciones en las que participan los varones o efectuando las adecuaciones necesarias para intentar compatibilizar su rol de madre, cuidadora y doméstica, con dicha participación. Es decir, no ha habido, en términos contundentes y generalizados, un cuestionamiento de la dicotomía entre lo público/privado que proyecte políticas públicas y normas que no sólo abran las puertas del espacio público para las mujeres, sino que a su vez abran las del espacio privado, las del hogar, para los hombres ${ }^{40}$. En otros términos, la clave para generar condiciones equitativas entre los hombres y las mujeres está en develar que no basta con abrir el espacio político, además se debe subvertir el espacio privado, descolonizando las categorías constitucionales tradicionales.

Bajo este entendido, la batalla por la igualdad formal y sustantiva debe ceder terreno a una que cuestione las reglas del juego del orden

40. Es conveniente precisar que Islandia, Dinamarca, Noruega y Suecia cuentan con interesantes políticas que abordan la redistribución de las labores domésticas de cuidado y crianza, como son las licencias parentales concebidas como un derecho individual intransferible, acompañada de una buena remuneración. VILLAVICENCIO, Luis y ZÚÑIGA, Alejandra, ob.cit, pág. 725.

Facultad de Derecho y Ciencias Sociales - Universidad de Valparaíso - Chile 
social. El enfoque no debe centrarse en "ganar la partida de los derechos", sino en subvertir los roles de género de manera de redefinir la ciudadanía de las mujeres y la de los hombres, generando nuevos derechos y deberes para ambos, en materia de crianza, cuidado y reproducción. Luego, esta subversión se entiende factible, por cuanto, de acuerdo a MacKinnon, el patriarcado no sólo da forma a las mujeres sino también a los hombres; "hombres y mujeres son socializados hacia una conducta de género estereotípica característica de su sexo" ${ }^{41}$. De ello se subentiende que los determinismos biológicos no caben para efectos la distribución de las funciones reproductivas y domésticas ya precisadas.

Para este propósito subversivo, es vital cesar en la visión dicotómica público/privado del orden social y reconocer que "el ámbito público no puede ser comprendido por completo en ausencia de la esfera privada, [pues ambos son] interdependientes" ${ }^{42}$. Es decir, es preciso ir a contracorriente de la lógica liberal reflejada en el contrato social en donde, según Rodríguez y Rubio-Marín, el individuo es un ser autónomo, libre e independiente, y no hay cabida para cuestionamientos acerca de la reconciliación de su autonomía personal y su responsabilidad con la dependencia. Es más, de acuerdo a este paradigma, la dependencia se presenta como "un enemigo externo contra el cual el hombre, naturalmente libre, debe defenderse a sí mismo. Así concebida, la independencia se vuelve un atributo esencial del individuo en la interpretación moderna del mismo, un atributo que el estado liberal tiene como un prerrequisito para acceder a la ciudadanía activa" ${ }^{43}$. En otros términos, parafraseando a Carol Pateman, no hay espacio para la figura fantasmal de la esposa que limpia la ropa del trabajador y prepara su vianda ${ }^{44}$, pues el contrato sexual desterró "la dependencia humana a la esfera privada, considerada terreno natural de las mujeres” ${ }^{\$ 5}$.

41. LEVYT, Nancy y VERCHICK, Robert, ob. cit., págs. 23-25.

42. PATEMAN, Carol: El contrato..., ob. cit, pág.13.

43. RODRÍGUEZ, Blanca y RUBIO-MARÍN, Ruth, ob. cit., pág. 308.

44. PATEMAN, Carol: El contrato..., ob. cit., pág. 183.

45. RODRÍGUEZ, Blanca y RUBIO-MARÍN, Ruth, ob. cit., pág. 311.

Revista de Ciencias Sociales - Número 69 (2016) - Universidad de Valparáíso - ISSN 0716-7725-Valparaíso, Chile

107 
En este sentido, se ha venido desarrollando a nivel europeo, un tercer modelo que intenta capturar las virtudes de ambas doctrinas, revalorizando las labores de cuidado, crianza y reproducción, y a la vez, intentando subvertir los roles tradicionales asignados a los géneros ${ }^{46}$.

Siguiendo a Rodríguez y Sacksofsky, en esta línea ha avanzado el Tribunal Constitucional alemán desde hace un tiempo, al afirmar en 1991 que en materia de custodia de los hijos, los padres (varones) también tienen derecho a cuidarlos y criarlos. Detrás de esta nueva línea de argumentos, sostienen las autoras, descansa el cambio en la visión del rol social del hombre. El rol del hombre en la familia ahora tiene más relevancia, a medida que se busca la igualdad sustantiva entre hombres y mujeres desde una perspectiva de grupo. Esto confirma que a fin de terminar con la dominación de los hombres sobre las mujeres, los roles sociales de ambos deben ser reformados. Enfatizar la presencia del hombre en la familia y la importancia de su rol como padre es crucial para este $\mathrm{fin}^{47}$.

En nuestro país, a nivel legislativo ha habido ciertas modificaciones que, aparentemente, van en esta dirección. Específicamente, las introducidas por la Ley N²0.680 de 2013 al Código Civil y por la Ley No 20.545 al Código del Trabajo, relativas al régimen de cuidado personal de los hijos y a la creación del postnatal parental, respectivamente.

La modificación introducida al Código Civil, estableció que el cuidado personal de los hijos se basa en el principio de corresponsabilidad (art. 224) y, que en caso de que los padres vivan separados y no exista acuerdo respecto al cuidado personal, los hijos continuarán bajo el cuidado personal del padre o madre con quien estén viviendo (inc. 3 art. 225). Así, se reemplazó el antiguo régimen de cuidado personal por defecto, que establecía que en el caso de que los padres vivieran separados, a la madre le correspondía el cuidado personal de

\footnotetext{
46. RUBIO-MARÍN, Ruth, ob. cit., pág. 807.

47. RODRÍGUEZ, Blanca y SACKSOFSKY, Ute: "Gender in the German Constitution”. En: Baines, Beverly y Rubio-Marín, Ruth: The Gender of Constitutional Jurisprudence, Cambridge University Press, 2005. Pág. 168.
}

Facultad de Derecho y Ciencias Sociales - Universidad de Valparaíso - Chile 
los hijos. No obstante lo anterior, el juez, velando por el interés superior del niño/a, puede atribuir el cuidado personal del hijo al otro de los padres, o radicarlo en uno solo de ellos, si por acuerdo existiese alguna forma de ejercicio compartido (inc. 4 art. 225).

Durante la vigencia del antiguo régimen de cuidado personal de los hijos por defecto - aunque cuestionado por su carácter discriminatorio en contra la mujer, tal como lo plantea Silva y Arab, pues presumía un "orden natural” que justificaba la preferencia legal de la madre como titular de la tuición de los hijos ${ }^{48}$ - el Tribunal Constitucional razonaba en el siguiente sentido, en relación a la referida disposición "[1]a regla de atribución preferente a la madre del cuidado personal de los hijos, no representa, por sí misma, una vulneración a la garantía de igualdad ante la ley, pues aunque introduzca una diferencia de trato entre la madre y el padre, la misma tiene justificación en la realidad social de nuestro país. La atribución provisoria del cuidado a la madre, quien usualmente lo conserva en el evento de separación, no hace sino confirmar una práctica arraigada en nuestra sociedad" 49 (C. $15^{\circ}$ y $16^{\circ}$ ). No obstante lo anterior, es posible observar tensiones sobre este punto. En efecto, en el mismo fallo citado, el voto disidente de los ministros Carmona, García y Brahm, planteó la inconstitucionalidad del derecho de custodia preferente de la mujer, por cuanto confería "a la madre una carga que, sostenida por la vía de los hechos y en prejuicios culturales, resulta desproporcionada en su relación con los deberes propios de la crianza de los hijos" (C. $24^{\circ}$ ). Asimismo, se estimó inconstitucional, porque discriminaba contra el padre al situarlo como suplente en la custodia de sus propios hijos: "constituye una exclusión en razón de un criterio sospechoso, el sexo. No importa su capacidad, su compromiso paterno, su disponibilidad de tiempo, su voluntad, sus méritos en su autoridad paternal" ${ }^{\prime 50}$ (C. $25^{\circ}$ ).

48. SILVA, Luis y ARAB, Jorge: "Legisladores y jueces frente a la igualdad constitucional de los sexos". En: Revista de derecho (Coquimbo), 21 (1), 2014. Nota 44, págs. 459 y 440.

49. Tribunal Constitucional, sentencia rol N²306-12, de 30 de mayo de 2013.
50. Ibíd.

Revista de Ciencias Sociales - Número 69 (2016) - Universidad de Valparaíso - ISSN 0716-7725-Valparaíso, Chile 
Con el régimen modificado, y eliminada a la madre de la primera línea para efectos de conceder el cuidado personal de los hijos, lo cierto es que las cosas no necesariamente van a mejorar las condiciones de igualdad entre los padres y las madres. Ello, por cuanto el principio que sigue rigiendo esta materia (como hasta antes de la modificación) no es el principio de igualdad entre hombres y mujeres, sino el "interés superior del niño". En efecto, durante la vigencia del antiguo régimen, siguiendo a Silva y Arab, la regla de atribución "legal prácticamente [coincidía] con la regla de atribución judicial [pues — de acuerdo a Lathrop- la preferencia materna aplicada por el juez se justificaba en que ella y el interés superior del niño hay sinonimia. Ello, estaría respaldado,] por ejemplo, por la Corte de Apelaciones de San Miguel, cuando dijo que, al entregar "la tuición de hijos menores a la madre en caso que los padres vivan separados, muestra que se hizo primar el principio del interés superior del niño por sobre el principio de igualdad, estimando que ello constituye un hecho natural, por ser la madre más idónea, regla que solo puede alterarse cuando el interés del niño lo haga indispensable, sea por maltrato, descuido y otra causa justificada, en cuyo caso faculta al juez para entregar su cuidado personal al otro de los progenitores" ${ }^{\prime \prime 1}$.

Así las cosas, no obstante derogado el régimen de cuidado personal que por defecto le concedía éste a la madre, subsiste la primacía del principio de interés superior del niño ${ }^{52}$, de manera que no se avanza, sólo por la referida modificación, en una redistribución más equitativa de las labores de crianza entre los padres ya que, por aplicación de este principio, al establecerse el régimen de cuidado judicialmente, no se observan mayores problemas para que los sesgos culturales que apuntan a la madre como la más idónea para realizar estas labores, se continúen filtrando.

51. SILVA, Luis y ARAB, Jorge: "Legisladores y jueces frente a la igualdad constitucional de los sexos”. En: Revista de derecho (Coquimbo), 21 (1), 2014. Nota 44, pág. 421.

52. Sobre el sentido y alcance del principio de corresponsabilidad y su relación con el principio del interés superior del niño, véase ACUÑA, Marcela (2013):

"El principio de corresponsabilidad parental". En: Revista de Derecho, Universidad Católica del Norte, año 20, $\mathrm{N}^{\circ}$ 2, 2013. Págs. 21-59.

Facultad de Derecho y Ciencias Sociales - Universidad de Valparaíso - Chile 
En cuanto a las normas sobre protección a la maternidad, específicamente al permiso "postnatal parental", el cual consiste en el derecho a descanso de maternidad, por un período que comienza a continuación del período de postnatal (una vez cumplidas las 12 semanas después del parto), pudiendo traspasarse al hombre, en la medida que ambos padres sean trabajadores, aunque la decisión es de la madre, y sólo procede este traspaso respecto de hasta seis de las doce semanas de postnatal parental jornada completa, o bien hasta doce de las dieciocho semanas de postnatal parental de jornada parcial.

No obstante el avance que supone la posibilidad de que el hombre pueda ejercer el permiso de postnatal parental, en la práctica, los traspasos de este permiso "de las madres a los padres... son claramente insuficientes en términos de facilitar una mayor corresponsabilidad del trabajo de cuidado entre hombres y mujeres así como el ejercicio efectivo de una paternidad más cotidiana" ${ }^{53}$. Esta realidad, se condice con posturas jurisprudenciales que han llegado a afirmar que "el permiso parental se centra fundamentalmente en el desarrollo sicológico del menor, mediante el apego a cualquiera de las figuras parentales progenitoras, aunque primariamente a la madre" ${ }^{54}$. No obstante ello, existen voces disidentes en estas instancias. Así, en causa del año 2013 sobre la constitucionalidad de ciertas normas relativas al postnatal parental, el voto en contra de los Ministros Carmona, García y VieraGallo destaca el avance que significó el postnatal parental, no sólo respecto de la protección a la maternidad, sino también en relación a “(...) la Corresponsabilidad parental, en que tanto el padre como la madre se hacen cargo del enorme trabajo que significa la crianza. Para ello es relevante comprender (...) que esta tarea no corresponde únicamente a las mujeres..." $\left(\text { C. } 3^{\circ}\right)^{55}$.

53. LUPICA, Carina: Corresponsabilidad de los cuidados y autonomía económica de las mujeres: Lecciones aprendidas del Permiso Postnatal Parental en Chile. Naciones Unidas, CEPAL, 2015. Pág. 41.

54. Tribunal Constitucional, Sentencia Rol 2250-12, de 18 de junio de 2013, considerando $29^{\circ}$ (la negrita es mía).

55. Tribunal Constitucional, sentencia rol N²250-12, de 18 de junio de 2013.

Revista de Ciencias Sociales - Número 69 (2016) - Universidad de Valparáiso - ISSN 0716-7725-Valparáís, Chile 
En atención a las breves referencias normativas y jurisprudenciales, es evidente que el rol del derecho y la interpretación que se haga de éste es determinante en la labor de subvertir el orden de género y revalorizar las labores de cuidado y reproductivas. Sin embargo, para que el derecho despliegue estas capacidades - y aunque resulte obvioes preciso apuntar en una dirección que, efectivamente, ponga en tensión los roles de género. En otras palabras, las modificaciones introducidas al Código Civil y al Código del Trabajo señaladas, sólo serán eficaces para efectos de reacomodar la distribución de las labores de cuidado, crianza y reproducción entre los padres, en la medida en que con su aplicación e interpretación se desafíen los estereotipos de género, desarraigando, por ejemplo, el sesgo cultural de que siempre el interés superior del niño coincide con que su cuidado personal le sea concedido a la madre, o, implementando el postnatal parental obligatorio para ambos padres, de manera que no se pueda determinar por acuerdo privado de las partes, el que el varón lo ejerza, o no.

Para desplegar la referida potencialidad del derecho, su operatividad pasa por una reinterpretación de la cláusula constitucional de igualdad - es de una perspectiva de género con base en las teorías feministas-, en tanto función clave para reconceptualizar la ciudadanía de los géneros, por cuanto dicha actividad hermenéutica permitirá cuestionar y poner en tensión los roles que se les han asignado a las mujeres y a los hombres en razón de su género.

Por perspectiva de género se entiende aquella "técnica con la que hacer frente a las desigualdades entre mujeres y hombres y a la discriminación de las mujeres (...) [y consiste en] tener en cuenta el impacto de género antes de que las decisiones sean adoptadas. Se trata de que los procesos políticos de toma de decisiones no sean rutinas "ciegas de género" o "sesgadas de género", es decir, que tengan en cuenta las diferentes consecuencias que esas decisiones públicas tienen en los hombres y en las mujeres. Estas diferencias son debidas a las relaciones desiguales de poder establecidas entre los géneros desde hace miles de años y la situación subordinada de las mujeres en la mayor parte de las sociedades, dominadas por el patriarcado" ${ }^{56}$. En lo que respecta al rol

56. CARMONA, Encarna: "La perspectiva de género y los derechos humanos". En: Carmona, Encarna: La perspectiva de género en los Sistemas Europeo e Interamericano de Derechos Humanos. Centro de Estudios Políticos y Constitucionales, 2015. Págs. 27 y 28.

Facultad de Derecho y Ciencias Sociales - Universidad de Valparaíso - Chile 
de la teoría feminista, de acuerdo a Hunter, si bien esta no constituye autoridad jurídica, la investigación empírica y el material político pueden ser incorporados como parte del razonamiento implicado en la creación de normas jurídicas, el diseño de políticas públicas o la resolución judicial de algún caso ${ }^{57}$. Tras este modo de emprender la labor interpretativa de la cláusula de igualdad, descansa una idea de ciudadanía entendida, no en un sentido dogmático constitucional sino, en términos filosófico-políticos, es decir, una que contiene las condiciones necesarias para que las personas concurran al demos plenamente.

Sobre esto último, y conforme a lo que se ha venido señalado, la referida interpretación en clave de género debe plantearse con miras a la nueva propuesta europea. Es decir, dicha labor hermenéutica habrá de tender hacia una revalorización de las labores de cuidado, crianza y reproducción, pero sin dejar de poner en tensión los roles de género.

Interpretada de este modo la cláusula de igualdad, es posible avanzar hacia un modelo de ciudadanía de género que tienda un puente entre lo público y lo privado, fundado en su interdependencia. De este modo, se sentarán las bases para reedificar un orden social que habilite el total despliegue de las capacidades ${ }^{58}$ de las mujeres, en el marco de una

57. HUNTER, Rosemary, "An Account of Feminist Judging”. En: Rosemary Hunter, Clare McGlynn y Erika Rackley: Feminist Judgments. From Theory to Practice. Hart Publishing, Oxford and Portland, Oregon, 2010. Pág. 43.

58. La idea del despliegue de las capacidades que se ha venido señalado, se enmarca en el denominado "enfoque de las capacidades" desarrollado por Martha Nussbaum, quien lo entiende como una herramienta que establece ciertos pilares fundamentales en una teoría mínima de justicia social, en combinación con una idea de la dignidad humana, asegurando a todos los ciudadanos un umbral límite de una lista de derechos claves, sobre la base de que son requisitos de una vida merecedora de dignidad humana. DIXON, Rosalind y NUSSBAUM, Martha: "Abortion, Dignity and a Capabilities Approach". En: Beverly Baines; Daphne BarakErez y TsviKahana: Feminist Constitutionalism.Global Perspectives. Cambridge University Press, 2012. Pág. 68. Estos derechos tienen por objeto algo más que la mera supervivencia humana: la prosperidad de la misma, y sin las cuales no consideraríamos una vida totalmente humana. HAY, Carol, ob. cit., pág. 33. Estas diez capacidades funcionales humanas centrales según Nussbaum son: la vida, la salud corporal, la integridad corporal, los sentidos, la imaginación y el pensamiento, las emociones, la razón práctica, la afiliación, el relacionarnos interesadamente con otras especies, la 
ciudadanía ${ }^{59}$ que cuestione los roles que cada género hasta ahora, han configurado, o por lo menos ejercen una importante influencia, en la manera en que las mujeres, y por cierto los hombres, se plantean como agentes morales en el demos, restringiendo el desarrollo moral de las primeras y ampliando el de los segundos.

En cuanto al reconocimiento de la interdependencia humana, ésta supone que para el propósito de la subversión de los roles de género, no basta establecer un modelo que facilite el acceso de las mujeres a la esfera de lo público, si no se hace lo propio con los varones en la de lo privado. De no suceder ello, no hay alteración de los roles de género. A lo sumo, las que carezcan de medios económicos o de una red de asistencia de cuidado, continuarán con la referida doble jornada, y las que gocen de esos privilegios, podrán delegar las labores de cuidado y crianza en terceros, perpetuándose, en los dos casos, el modelo que da por supuesto que el individuo (hombre o mujer) presente en el escenario de lo público, es un ser independiente, que no necesita conciliar su autonomía con las labores del hogar ${ }^{60}$, replicando el modelo actual y conservando la comprensión dicotómica del orden social.

Por último, en cuanto al establecimiento de un orden social que aspire a una ciudadanía que permita el despliegue de las capacidades de las mujeres y los hombres, pese a que son las mujeres las que están presas en esta estructura opresiva de la que se ha venido hablando, es preciso tener presente lo siguiente: la reasignación de roles de género supone que la corresponsabilidad en las labores domésticas de crianza,

capacidad de jugar y tener control del entorno. GOUGH, Ian: "El enfoque de las capacidades de M. Nussbaum: un análisis comparado con nuestra teoría de las necesidades humanas”. En: Papeles de relaciones ecosociales y cambio global, vol. 100, 2007. Pág. 183.

59. Sobre la evolución del concepto de ciudadanía con enfoque de género, véase ZÚÑIGA, Yanira: "Ciudadanía y Género. Representaciones y conceptualizaciones en el pensamiento moderno y contemporáneo”. En: Revista de Derecho, Universidad Católica del norte, año 17, N², 2010. Págs. 133-163.

60. Sobre la idea de la interdependencia humana, véase RODRÍGUEZ, Blanca y RUBIO-MARÍN, Ruth, ob. cit. págs. 311-314.

Facultad de Derecho y Ciencias Sociales - Universidad de Valparaíso - Chile 
cuidado y reproducción no sólo implica trasladar nuevas cargas al hombre que ingresa al hogar, sino también una serie de derechos asociados a la posibilidad de participar en el cuidado y crianza de los hijos, y la conservación de la vida doméstico.

\section{Conclusiones}

El presente trabajo ha planteado la necesidad de aproximarse al problema de la opresión estructural que aqueja a las mujeres a nivel global y que las ha condenado a una ciudadanía de "segunda clase", mediante la interpretación, desde una perspectiva de género con base en las teorías feministas, de la cláusula constitucional de igualdad. Hombres y mujeres son prescriptivamente iguales, tienen igual derecho a desplegar sus capacidades en tanto agentes morales. Sin embargo, los roles atribuidos a cada género los/las predefinen a realizar —o no realizar - ciertas funciones en el orden social, especialmente en relación al aspecto doméstico, que impide su realización plena en tanto miembros del demos. Por ello, es preciso articular la cláusula de igualdad prescindiendo de los roles tradicionales con afán de subvertirlos. Con ello, se perfila un nuevo modelo de ciudadanía de género donde gobierne la corresponsabilidad en las labores de cuidado, crianza y de reproducción.

La necesidad de un nuevo modelo de ciudadanía de género se justificó mediante la revisión de la situación de las mujeres en el marco de la falsa promesa que les significó la reivindicación de los derechos de la igualdad, libertad y fraternidad de la modernidad. Asimismo, se señalaron las vías por las que se ha intentado dar la batalla para erradicar la subordinación femenina amparada en la lógica dicotómica público/ privado del orden social, así como también las debilidades de las mismas.

Luego, una vez demostrado que la dinámica de la igualdad de los sexos, ya sea formal o sustantiva, no ha resultado eficaz para el despliegue total de las capacidades de las mujeres en tanto ciudadanas - por cuanto la diferencia sexual aún trae aparejada diferencias políticas; la independencia de la vida privada de la pública permanece intacta y; los esmeros por incorporar a las mujeres a la esfera pública han desatendido la urgencia de arrimar a los varones al hogar-, la

Revista de Ciencias Sociales - Número 69 (2016) - Universidad de Valparáíso - ISSN 0716-7725-Valparaíso, Chile 
propuesta de una interpretación de la cláusula de igualdad en clave de género, conforme a la nueva tendencia europea que revaloriza las labores de cuidado, crianza y reproducción, a la vez que tiene en la mira la subversión de los géneros, parece del todo coherente, pues se hace cargo de un aspecto no abordado por los otros modelos, cual es: la redistribución de las mencionadas labores, aspecto crucial para cualquier rediseño estructural de la sociedad, debido a que implica alterar los roles tradicionales de género.

Para finalizar, conviene recordar que, a nivel nacional, la coherencia de esta propuesta no se sostiene en el vacío pues, tal como se señaló en la última parte, existen tendencias jurisprudenciales, así como también avances en materias legislativas que, aunque incipientes, poco a poco van haciendo el camino para que en algún momento, efectivamente, los roles de género puedan ser subvertidos, dando lugar a una nueva ciudadanía que faculte el despliegue de las capacidades tanto de las mujeres y de los hombres. Por último, y sin abandonar los fines emancipatorios que subyacen a toda esta reflexión, los cambios planteados no aspiran únicamente a reasignar nuevos derechos para las mujeres y nuevas cargas para los varones, sino lo uno y lo otro respecto de cada uno de ellos, pero esta vez de manera equitativa.

\section{BIBLIOGRAFÍA}

AGUILERA, Daniela, VÁSQUEZ, Andrea y ZÚÑIGA, Alejandra:

"Lejos del poder. Hacia la implementación de una ley de cuotas en Chile". En: Revista de Derecho (Valdivia), vol. XX, N 2, 2007. Págs. 9-30.

BALAGUER, María Luisa: Mujer y Constitución. La construcción jurídica del género, Ediciones Cátedra, Universitat de València, 2005.

BELTRÁN, Elena: "Justicia, democracia y ciudadanía: las vías hacia la igualdad”. En: Beltrán, Elena y Maquieira, Virginia: Feminismo.

Debates teóricos contemporáneos. Alianza, Madrid, 2008. Págs. 191-228.

BENHABIB: "El otro generalizado y el otro concreto: la controversia Kohlber-Gilligan y la teoría feminista”. En: Benhabib y Cornell:

Teoría Feminista y Teoría Critica. Ensayos sobre la política de género en las

Facultad de Derecho y Ciencias Sociales - Universidad de Valparaíso - Chile 
sociedades de capitalismo tardío. Alfons el Magnànim, Institució Valenciana d'Estudis i Investigació, España, 1990. Págs.119-150.

CARMONA, Encarna: "La perspectiva de género y los derechos humanos". En: Carmona, Encarna: La perspectiva de género en los

Sistemas Europeo e Interamericano de Derechos Humanos. Centro de Estudios Políticos y Constitucionales, Madrid, 2015. Págs. 25-42.

DIXON, Rosalind y NUSSBAUM, Martha: "Abortion, Dignity and a Capabilities Approach”. En: Beverly Baines; Daphne Barak-Erez

y TsviKahana: Feminist Constitutionalism. Global Perspectives. Cambridge University Press, 2012. Págs. 64-80.

GOUGH, Ian: "El enfoque de las capacidades de M. Nussbaum: un análisis comparado con nuestra teoría de las necesidades humanas”. En: Papeles de relaciones ecosociales y cambio global, vol. 100, 2007. Págs. 177-202.

HAY, Carol: Kantianism, Liberalism and Feminism. Resisting Oppression, Palgrave Macmillan, New York, 2013.

HUNTER, Rosemary: "An Account of Feminist Judging”. En: Rosemary Hunter, Clare McGlynn y Erika Rackley: Feminist

Judgments. From Theory to Practice. Hart Publishing, Oxford and Portland, Oregon, 2010. Págs. 30-43.

LEVYT, Nancy y VERCHICK, Robert: Feminist Legal Theory. A Primer. New York University press, 2006.

LUPICA, Carina: Corresponsabilidad de los cuidados y autonomía económica de las mujeres: Lecciones aprendidas del Permiso Postnatal

Parental en Chile. Naciones Unidas, CEPAL, 2015.

PATEMAN, Carol: El contrato sexual. Barcelona: Anthropos, México: Universidad Autónoma Metropolitana-Iztapalapa, Trad. María Luisa Femenías, 1995.

- "Equality, difference, subordination: the politics of motherhood and Women's citizenship". En: Bock, Gisela y James, Susan: Beyond equality and difference: citizenship, feminist politics and female subjectivity. Routledge, Londres y Nueva York, 2005. Págs. 17-31.

RODRÍGUEZ, Blanca y RUBIO-MARÍN, Ruth: "The Gender of Representation: On Democracy, Equality, and Parity".

En: International Journal of Constitutional Law, vol. 6, $\mathrm{N}^{\circ}$ 2, 2008. Págs. 287-316.

Revista de Ciencias Sociales - Número 69 (2016) - Universidad de Valparaíso - ISSN 0716-7725-Valparáís, Chile 
RODRÍGUEZ, Blanca y SACKSOFSKY, Ute: "Gender in the German Constitution”. En: Beverly Baines y Ruth Rubio-Marín: The Gender of Constitutional Jurisprudence. Cambridge University Press, 2005. Págs. 149-173.

RUBIO-MARÍN, Ruth: "The (dis) establishment of gender: Care and gender roles in the family as a constitutional matter". En:

International Journal of Constitutional Law, vol. 13, $\mathrm{n}^{\circ} 4,2015$. Págs. 787-818.

SÁNCHEZ, Cristina (2008): “Genealogía de la vindicación”. En: Beltrán, Elena y Maquieira, Virginia: Feminismo. Debates teóricos contemporáneos. Alianza, Madrid, 2008. Págs. 17-74.

SILVA, Luis \& ARAB, Jorge: "Legisladores y jueces frente a la igualdad constitucional de los sexos". En: Revista de derecho (Coquimbo), 21(1), 2014. Págs. 443-473.

VALENZUELA, Cecilia y VILLAVICENCIO, Luis (2015): "La constitucionalización de los derechos sexuales y reproductivos. Hacia una igual ciudadanía para las mujeres". En: Revista Ius et Praxis, año 21, n¹. Págs. 271-314.

VALENZUELA, Cecilia y ZÚÑIGA, Alejandra: "Leyes de cuotas electorales, constitución y democracia". En: Revista de Derecho

(Valdivia), XXVII, N 1, 2014. Págs. 191- 211.

VILLAVICENCIO, Luis y ZÚÑIGA, Alejandra: "La violencia de género como opresión estructural”. En: Revista de Derecho, vol. 42, $\mathrm{N}^{\circ}$ (2015). Págs. 719-728.

YOUNG, Iris Marion: La justicia y la política de la diferencia, Ediciones Cátedra, Madrid, 2000.

ZÚNIIGA, Yanira: "Democracia paritaria: de la teoría a la práctica". En: Revista de Derecho (Valdivia), XVIII, No 2, 2005. Pp. 131154.

"La "generización" de la ciudadanía. Apuntes sobre el rol de la diferencia sexual en el pensamiento feminista”. En: Revista de Derecho, vol. XXII- Nº 2, 2009. Págs. 39-64.

__ "Ciudadanía y Género. Representaciones y conceptualizaciones en el pensamiento moderno y contemporáneo". En: Revista de Derecho, Universidad Católica del norte, año 17, $N^{\circ}$ 2, 2010. Pág. 133-163.

Facultad de Derecho y Ciencias Sociales - Universidad de Valparaíso - Chile 
La cláusula constitucional de igualdad en clave de género: hacia un nuevo...

\section{Jurisprudencia citada}

Tribunal Constitucional, Sentencia rol $\mathrm{N}^{\circ}$ 2306-12, de 30 de mayo de 2013.

Tribunal Constitucional, Sentencia rol N²250-12, de 18 de junio de 2013.

Revista de Ciencias Sociales - Número 69 (2016) - Universidad de Valparáíso - ISSN 0716-7725-Valparaíso, Chile 